\title{
PERBEDAAN INKLINASI INSISIVUS PADA PASIEN MALOKLUSI KLAS I DAN KLAS II SKELETAL DENGAN POLA PERNAFASAN NORMAL DAN PERNAFASAN MELALUI MULUT
}

\author{
(INCISOR INCLINATION IN PATIENTS WITH MALOCCLUSION \\ OF CLASS I AND CLASS II SKELETAL WITH NORMAL \\ AND MOUTH BREATHING PATTERN)
}

\author{
Hilda Fitria Lubis, Nishanthi Selvarajoo
}

Departemen Ortodonsia

Fakultas Kedokteran Gigi, Universitas Sumatera Utara

Jl. Alumni No. 2 Kampus USU Medan 20155

E-mail: hildadrgusu@gmail.com

\begin{abstract}
Respiration is the process of inhalation and exhalation of air into and out of the lungs. In normal respiration, air is breathed in and out through the nose. Mouth breathing occurs due to the difficulty in breathing through the nose. Breathing through the mouth can change the posture of the head, jaw and tongue, and this will alter the balance of pressure in the jaw and teeth thus affecting the growth of the jaw and tooth position. The purpose of this study is to determine the difference of inclination of the maxillary and mandibular incisor, and interincisal angle in malocclusion of Class I and Class II skeletal with normal and mouth breathing pattern. This was a descriptive study using 44 lateral cephalometric samples consisted normal and mouth breathing patients aged 8-12 years. The mean and standard deviation was calculated for inclination of the maxillary and mandibular incisor, and interincisal angle. The analyzed result by independent $t$-test showed that there were significant differences $(\mathrm{p}<0.05)$ in maxillary inclination and interincisal angle of Class I skeletal and maxillary inclination (degree), linear measurement of mandibular inclination and interincisal angle of Class II skeletal patients between normal and mouth breathing.
\end{abstract}

Key words: mouth breathing, incisor inclination, interincisal angle

\begin{abstract}
Abstrak
Pernafasan atau respirasi adalah proses masuk dan keluarnya udara ke dalam dan keluar paru-paru. Pada pernafasan normal, udara masuk dan keluar melalui hidung. Pernafasan mulut terjadi karena adanya kesulitan dalam bernafas melalui hidung. Bernafas melalui mulut dapat mengubah postur kepala, rahang dan lidah, dan ini akan mengubah keseimbangan tekanan pada rahang dan gigi serta mempengaruhi pertumbuhan rahang dan posisi gigi. Tujuan penelitian ini adalah untuk mengetahui perbedaan inklinasi gigi insisivus maksila, inklinasi dan mandibula serta sudut interinsisal pada pasien maloklusi Klas I dan Klas II skeletal dengan pola pernafasan normal dan pernafasan melalui mulut. Penelitian ini merupakan penelitian deskriptif yang menggunakan 44 foto sefalometri lateral pasien yang bernafas normal dan bernafas melalui mulut berusia antara 8-12 tahun. Analisis data dilakukan dengan menghitung rerata dan standar deviasi inklinasi gigi insisivus maksila, inklinasi gigi insisivus mandibula dan sudut interinsisal. Hasil uji-t Independen menunjukkan nilai rerata derajat dan ukuran linear inklinasi gigi insisivus maksila dan sudut interinsisal pada maloklusi Klas I skeletal dan derajat inklinasi gigi insisivus maksila, ukuran linear inklinasi gigi insisivus mandibula dan sudut interinsisal pada maloklusi Klas II skeletal antara pernafasan normal dan pernafasan melalui mulut terdapat perbedaan yang signifikan.
\end{abstract}

Kata kunci: pernafasan mulut, inklinasi insisivus, sudut interinsisal

\section{PENDAHULUAN}

Pernafasan atau respirasi adalah proses masuk dan keluarnya udara ke dalam dan keluar paru-paru. Sistem pernafasan berfungsi untuk menyediakan suplai oksigen $\left(\mathrm{O}_{2}\right)$ dan mengeluarkan karbon dioksida 
$\left(\mathrm{CO}_{2}\right)$ dari dalam tubuh. Bernafas melalui mulut adalah suatu keadaan abnormal yang terjadi karena adanya kesulitan dalam bernafas melalui hidung, sehingga kebutuhan pernafasan tersebut dipenuhi lewat mulut. ${ }^{1,2}$

Pernafasan melalui mulut terjadi akibat obstruksi nasal dan nasofaring. ${ }^{3-5}$ Pernafasan melalui mulut dapat mengubah postur kepala, rahang dan lidah. ${ }^{3,6}$ Pada pasien yang bernafas melalui mulut, posisi lidah rendah dan ke belakang, jika perubahan postural ini berlangsung terus menerus akan mengakibatkan tinggi wajah bertambah, mandibula berotasi ke bawah dan ke belakang, tekanan otot buksinator meningkat sehingga menyebabkan lengkung maksila menjadi sempit. ${ }^{1,6-11}$ Menurut Sollow dan Hellsing, bernafas melalui mulut dapat menyebabkan tekanan bibir atas terhadap gigi insisivus maksila berkurang dan tekanan bibir bawah terhadap gigi insisivus mandibula bertambah. Saat membuka mulut, posisi bibir atas tidak dalam keadaan menekan gigi-gigi anterior, sedangkan bibir bawah yang berfungsi menahan tepi insisal gigi-gigi anterior maksila terletak lebih ke depan dari normal. ${ }^{12}$ Posisi bibir bawah yang terletak lebih ke depan dari normal merupakan faktor pendorong gigi-gigi anterior maksila bergerak ke labial. ${ }^{1}$ Insisivus maksila (I.NA) pada orang yang bernafas melalui mulut lebih protrusi karena penempatan bibir bawah yang hipertonus diantara insisivus maksila dan insisivus mandibula. ${ }^{2,11}$ Menurut Cabrera dkk. pada pasien dengan maloklusi Klas II divisi 1 Angle, ukuran linear inklinasi gigi insisivus maksila dan mandibula lebih besar pada pernafasan melalui mulut. ${ }^{3}$ Penelitian yang dilakukan oleh Subtelny dan Solow, diperoleh retroklinasi insisivus maksila terhadap garis Sella ke Nasion (S-N) pada pasien yang bernafas melalui mulut. ${ }^{1}$

Penelitian ini bertujuan untuk membandingkan inklinasi gigi insisivus maksila, inklinasi gigi insisivus mandibula dan sudut interinsisal pada pasien maloklusi Klas I dan Klas II skeletal dengan pernafasan normal (hidung) dan pernafasan melalui mulut dilihat dari sefalometri lateral.

\section{BAHAN DAN METODE}

Penelitian ini adalah penelitian deskriptif. Sampel pada penelitian ini sebanyak 44 foto sefalometri lateral pasien dengan pola pernafasan normal (hidung) dan pernafasan melalui mulut yang datang ke Klinik Ortodonti RSGM-P FKG USU pada tahun 20092013. Seluruh sampel pada penelitian ini harus memenuhi kriteria inklusi: foto sefalometri lateral pasien maloklusi Klas I dan Klas II skeletal yang berusia 8-12 tahun dengan pernafasan normal (hidung) dan pernafasan melalui mulut, belum pernah men- dapat perawatan ortodonti, pasien yang datang ke RSGM-P FKG USU dari tahun 2009-2013, kesehatan umum yang baik dan kriteria ekslusi: pasien yang sudah pernah dirawat ortodonti, kesehatan umum yang kurang baik, dan foto sefalometri lateral yang rusak. Penelitian dilakukan setelah mendapatkan persetujuan dari komisi etik USU (Health Research Ethical Committee of North Sumatera). Pernafasan normal dan pernafasan melalui mulut diperoleh dari status pasien dan roentgen foto sefalometri lateral menurut analisis McNamara yang mana lebar saluran udara pharynx atas pada fase gigi bercampur rata-rata $12 \mathrm{~mm}^{13}$ Pengumpulan data dilakukan dengan pengukuran derajat dan ukuran linear inklinasi gigi insisivus maksila dan mandibula serta sudut interinsisal. Pada sefalometri dilakukan penapakan dengan kertas asetat dan pensil di atas tracing box untuk menentukan titik-titik referensi yaitu, sella (S), nasion (N), subspinal (A) dan supramental (B). Metode pengukuran inklinasi insisivus dalam penelitian ini adalah dengan menggunakan metode Steiner. ${ }^{2,1418}$ Maloklusi Klas I dan Klas II skeletal dapat dilihat pada besar sudut ANB, dimana sudut ANB terbentuk dari selisih antara sudut SNA dan SNB. Inklinasi gigi insisivus maksila ditentukan melalui garis yang ditarik dari nasion $(\mathrm{N})$ ke titik A dan inklinasi aksial gigi insisivus maksila ditentukan melalui garis yang ditarik dari tepi insisal gigi insisivus maksila ke apeks akar gigi insisivus maksila serta ukuran linear gigi insisivus maksila ditentukan melalui garis yang ditarik dari permukaan gigi insisivus paling labial terhadap garis $\mathrm{N}-\mathrm{A}$. Inklinasi gigi insisivus mandibula ditentukan melalui garis yang ditarik dari nasion $(\mathrm{N})$ ke titik B dan inklinasi aksial gigi insisivus mandibular ditentukan melalui garis yang ditarik dari tepi insisal gigi insisivus mandibula ke apeks akar gigi insisivus mandibula serta ukuran linear gigi insisivus mandibula ditentukan melalui garis yang ditarik dari permukaan gigi insisivus paling labial terhadap garis N-B. Sudut interinsisal merupakan perpanjangan garis dari tepi insisal dan apeks akar gigi insisivus maksila dan insisivus mandibula. Analisis data dilakukan dengan menggunakan uji-t Independen untuk melihat perbedaan inklinasi insisivus pada pasien maloklusi Klas I dan Klas II skeletal dengan pola pernafasan normal dan pernafasan melalui mulut.

\section{HASIL}

Tabel 1 menunjukkan nilai rerata derajat inklinasi gigi insisivus maksila (I.NA) pada pernafasan normal sebesar $23,77^{\circ}$ sedangkan pada pernafasan melalui mulut sebesar $29,03^{\circ}$. Nilai rerata ukuran linear 
inklinasi gigi insisivus maksila (I-NA) pada pernafasan normal 5,11 mm sedangkan pernafasan melalui mulut $7,47 \mathrm{~mm}$.

Tabel 1. Nilai rerata inklinasi gigi insisisvus maksila antara pernafasan normal (hidung) dan pernafasan melalui mulut pada maloklusi Klas I skeletal

\begin{tabular}{|c|c|c|c|}
\hline Pengukuran & $\mathrm{n}$ & Rerata & $\mathrm{p}$ \\
\hline $\begin{array}{l}\text { Inklinasi gigi insisisvus maksila } \\
\text { (I.NA) }\left(^{\circ}\right) \text { melalui hidung }\end{array}$ & 11 & $23,77 \pm 2,02$ & \multirow{2}{*}{0,000} \\
\hline $\begin{array}{l}\text { Inklinasi gigi insisisvus maksila } \\
\left(\text { I.NA) }\left(^{\circ}\right) \text { melalui mulut }\right.\end{array}$ & 15 & $29,03 \pm 2,93$ & \\
\hline $\begin{array}{l}\text { Inklinasi gigi insisisvus maksila } \\
\text { (I-NA) (mm) melalui hidung }\end{array}$ & 11 & $5,11 \pm 1,09$ & \multirow[b]{2}{*}{0,003} \\
\hline $\begin{array}{l}\text { Inklinasi gigi insisisvus maksila } \\
\text { (I-NA) (mm) melalui mulut }\end{array}$ & 15 & $7,47 \pm 2,18$ & \\
\hline
\end{tabular}

Hasil uji-t Independen pada maloklusi Klas I skeletal antara pernafasan normal (hidung) dan mulut, diperoleh nilai rerata derajat inklinasi gigi insisivus maksila (I.NA) pada pernafasan melalui mulut berbeda secara signifikan dengan pernafasan normal $(\mathrm{p}=0,000)$. Nilai rerata ukuran linear inklinasi gigi insisivus maksila (I-NA) juga diperoleh ada perbedaan secara signifikan $(\mathrm{p}=0,003)$ antara pernafasan melalui mulut dan pernafasan normal.

Tabel 2. Nilai rerata inklinasi gigi insisivus mandibula antara pernafasan normal (hidung) dan pernafasan melalui mulut pada maloklusi Klas I skeletal

\begin{tabular}{lccc}
\hline Pengukuran & $\mathrm{n}$ & Rerata & $\mathrm{P}$ \\
\hline $\begin{array}{l}\text { Inklinasi gigi insisivus mandibula } \\
\text { (I.NB) ( }\end{array}$ & 11 & $25,82 \pm 3,28$ & \\
$\begin{array}{l}\text { Inklinasi gigi insisivivus mandibula } \\
\text { (I.NB) }\end{array}$ & 15 & $28,10 \pm 2,47$ & 0,054 \\
\hline $\begin{array}{l}\text { Inklinasi gigi insisivivus mandibula } \\
\text { (I-NB) (mm) melalui hidung }\end{array}$ & 11 & $6,30 \pm 1,83$ & \\
$\begin{array}{l}\text { Inklinasi gigi insisivus mandibula } \\
\text { (I-NB) (mm) melalui mulut }\end{array}$ & 15 & $6,78 \pm 1,20$ & 0,420 \\
*signifikan pada $<<0,05$ & & & \\
\hline
\end{tabular}

Tabel 2 menunjukkan nilai rerata derajat inklinasi gigi insisivus mandibula (I.NB) pada pernafasan normal $25.82^{\circ}$ sedangkan pada pernafasan melalui mulut $28,10^{\circ}$. Nilai rerata ukuran linear inklinasi gigi insisivus mandibula (I-NB) pada pernafasan normal $6,30 \mathrm{~mm}$ sedangkan pada pernafasan melalui mulut $6,78 \mathrm{~mm}$.

Hasil uji-t Independen pada maloklusi Klas I skeletal antara pernafasan normal (hidung) dan mulut, diperoleh nilai rerata derajat inklinasi gigi insisivus mandibula (I.NB) tidak berbeda secara signifikan $(\mathrm{p}=0,054)$. Nilai rerata ukuran linear inklinasi gigi insisivus mandibula (I-NB) menunjukkan perbedaan secara tidak signifikan $(\mathrm{p}=0,420)$ antara pernafas- an melalui mulut dan pernafasan normal.

Tabel 3. Nilai rerata sudut interinsisal antara pernafasan normal (hidung) dan pernafasan melalui mulut pada maloklusi Klas I skeletal

\begin{tabular}{lccc}
\hline Pengukuran & $\mathrm{n}$ & Rerata & $\mathrm{p}$ \\
\hline $\begin{array}{l}\text { Sudut interinsisal (I.I) } \\
\left(^{\circ}\right) \text { melalui hidung }\end{array}$ & 11 & $127,02 \pm 4,50$ & \\
$\begin{array}{l}\text { Sudut interinsisal (I.I) }\left({ }^{\circ}\right) \\
\text { melalui mulut }\end{array}$ & 15 & $120,47 \pm 4,34$ & $0,001^{*}$ \\
\hline *signifikan pada p $<0,05$ & & & \\
\hline
\end{tabular}

Tabel 3 menunjukkan nilai rerata sudut interinsisal (I.I) pada pernafasan normal $127,02^{\circ}$ sedangkan pada pernafasan melalui mulut $120,47^{\circ}$.

Hasil uji-t Independen pada maloklusi Klas I skeletal antara pernafasan normal (hidung) dan mulut, diperoleh nilai rerata sudut interinsisal (I.I) perbedaan signifikan $(\mathrm{p}=0,001)$.

Tabel 4. Nilai rerata inklinasi gigi insisivus maksila antara pernafasan normal dan pernafasan melalui mulut pada maloklusi Klas II skeletal

\begin{tabular}{lccc}
\hline Pengukuran & $\mathrm{n}$ & Rerata & $\mathrm{p}$ \\
\hline $\begin{array}{l}\text { Inklinasi gigi } \\
\text { insisivus maksila }\end{array}$ & & $22,11 \pm 2,61$ & \\
$(\mathrm{I} . \mathrm{NA})\left(^{\circ}\right)$ & 11 & & \\
melalui hidung & & & $0,001^{*}$ \\
Inklinasi gigi & & & \\
insisivus maksila & & $27,32 \pm 2,36$ & \\
$(\mathrm{I} . \mathrm{NA})\left({ }^{\circ}\right)$ & & & \\
melalui mulut & 7 & & \\
\hline
\end{tabular}

Tabel 4. Nilai rerata inklinasi gigi insisivus maksila antara pernafasan normal dan pernafasan melalui mulut pada maloklusi Klas II skeletal (lanjutan)

\begin{tabular}{lccc}
\hline Pengukuran & $\mathrm{n}$ & Rerata & $\mathrm{p}$ \\
\hline Inklinasi gigi insisivus maksila & 11 & $4,59 \pm 1,24$ & \\
(I-NA) (mm) melalui hidung & & & 0,168 \\
Inklinasi gigi insisivus maksila & 7 & $5,36 \pm 0,80$ & \\
(I-NA) (mm) melalui mulut & & & \\
*signifikan pada p<0,05 & & &
\end{tabular}

Tabel 4 menunjukkan nilai rerata derajat inklinasi gigi insisivus maksila (I.NA) pada pernafasan normal $22,11^{\circ}$ sedangkan pada pernafasan melalui mulut $27,32^{\circ}$. Nilai rerata ukuran linear inklinasi gigi insisivus maksila (I-NA) pada pernafasan normal 4,59 $\mathrm{mm}$ sedangkan pada pernafasan melalui mulut $5,36 \mathrm{~mm}$.

Hasil uji-t Independen pada maloklusi Klas II skeletal, antara pernafasan normal (hidung) dan mulut, diperoleh nilai rerata derajat inklinasi gigi insisivus maksila (I.NA) pada pernafasan melalui mulut berbeda secara signifikan $(\mathrm{p}=0,001)$ dengan pernafasan normal. Nilai rerata ukuran linear inklinasi gigi in- 
sisivus maksila (I-NA) diperoleh tidak ada perbedaan secara signifikan $(\mathrm{p}=0,168)$ antara pernafasan normal dan mulut.

Tabel 5. Nilai rerata inklinasi gigi insisivus

\begin{tabular}{lccc}
\hline Pengukuran & $\mathrm{n}$ & Rerata & $\mathrm{p}$ \\
\hline $\begin{array}{l}\text { Inklinasi gigi insisivus } \\
\text { mandibula (I.NB) }\left({ }^{\circ}\right)\end{array}$ & 11 & $27,18 \pm 3,23$ & \\
$\begin{array}{l}\text { melalui hidung } \\
\text { Inklinasi gigi insisivus }\end{array}$ & 7 & $30,14 \pm 2,54$ & 0,058 \\
$\begin{array}{l}\text { mandibula (I.NB) }\left({ }^{\circ}\right) \\
\text { melalui mulut }\end{array}$ & & & \\
\hline
\end{tabular}

Tabel 5. Nilai rerata inklinasi gigi insisivus (lanjutan)

\begin{tabular}{lccc}
\hline Pengukuran & $\mathrm{n}$ & Rerata & $\mathrm{p}$ \\
\hline $\begin{array}{l}\text { Inklinasi gigi insisivus } \\
\text { mandibula (I-NB) }(\mathrm{mm})\end{array}$ & 11 & $6,91 \pm 1,52$ & $0,043^{*}$ \\
$\begin{array}{l}\text { melalui hidung } \\
\text { Inklinasi gigi insisivus } \\
\text { mandibula (I-NB) (mm) } \\
\text { melalui mulut }\end{array}$ & 7 & $8,61 \pm 1,72$ & \\
*signifikan pada $<<0,05$ & & &
\end{tabular}

Tabel 5 menunjukkan nilai rerata derajat inklina-si gigi insisivus mandibula (I.NB) pada pernafasan normal $27,18^{\circ}$ sedangkan pada pernafasan melalui mulut $30,14^{\circ}$. Nilai rerata ukuran linear inklinasi gigi insisivus mandibula (I-NB) pada pernafasan normal $6,91 \mathrm{~mm}$ sedangkan pada pernafasan melalui mulut 8,61 mm. Hasil uji-t Independen pada maloklusi Klas II skeletal antara pernafasan normal (hidung) dan mulut, diperoleh nilai rerata derajat inklinasi gigi insisivus mandibula (I.NB) menunjukkan perbedaan yang tidak signifikan $(\mathrm{p}=0,058)$. Nilai rerata ukuran linear inklinasi gigi insisivus mandibula (I-NB) diperoleh ada perbedaan secara signifikan $(\mathrm{p}=0,043)$ antara pernafasan melalui mulut dan pernafasan normal.

Tabel 6. Nilai rerata sudut interinsisal antara pernafasan normal (hidung) dan pernafasan melalui mulut pada maloklusi Klas II skeletal

\begin{tabular}{lccc}
\hline Pengukuran & $\mathrm{n}$ & Rerata & $\mathrm{P}$ \\
\hline $\begin{array}{l}\text { Sudut interinsisal (I.I) }\left({ }^{\circ}\right) \\
\text { melalui hidung }\end{array}$ & 11 & $124,09 \pm 5,07$ & \\
$\begin{array}{l}\text { Sudut interinsisal (I.I) }\left({ }^{\circ}\right) \\
\text { melalui mulut }\end{array}$ & 7 & $117,07 \pm 5,62$ & $0,014^{*}$ \\
\hline *signifikan pada $\mathrm{p}<0,05$ & & & \\
\hline sika & & &
\end{tabular}

Tabel 6 menunjukkan nilai rerata sudut interinsisal (I.I) pada pernafasan normal $124,09^{\circ}$ sedangkan pada pernafasan melalui mulut $117,07^{\circ}$.

Hasil uji-t Independen pada maloklusi Klas II skeletal antara pernafasan normal dan mulut, diperoleh nilai rerata sudut interinsisal (I.I) menunjukkan perbedaan secara signifikan $(\mathrm{p}=0,014)$.

\section{PEMBAHASAN}

Pada penelitian ini, dilakukan pengukuran inklinasi gigi insisivus maksila, inklinasi gigi insisivus mandibula dan sudut interinsisal pada roentgen foto sefalometri lateral pasien yang datang ke RSGMP FKG USU dari tahun 2009-2013.

Pada Tabel 1, dapat dilihat nilai rerata derajat dan ukuran linear inklinasi gigi insisivus maksila (I.NA dan I-NA) untuk pasien maloklusi Klas I skeletal pada kelompok dengan pola pernafasan melalui mulut lebih besar dan berbeda secara signifikan $(\mathrm{p}<0,05)$. Tabel 5 menunjukkan nilai rerata derajat inklinasi gigi insisivus maksila (I.NA) untuk maloklusi Klas II skeletal pada kelompok dengan pola pernafasan melalui mulut lebih besar dan berbeda secara signifikan $(\mathrm{p}<0,05)$ dibandingkan kelompok dengan pola pernafasan normal (hidung). Hasil penelitian ini sesuai dengan penelitian yang dilakukan oleh Juliano dkk. yang memperoleh hasil nilai rerata inklinasi gigi insisivus maksila menunjukkan inklinasi bukal yang lebih besar pada anak yang bernafas melalui mulut dan ukuran linear pada insisivus maksila menunjukkan inklinasi lebih ke anterior pada anak yang bernafas melalui mulut. ${ }^{2} \mathrm{Mc}$ Coy dan Hellsing menyatakan bahwa posisi bibir bawah yang hipertonus merupakan faktor predisposisi terjadinya gigi-gigi anterior maksila yang protrusi. ${ }^{1}$

Berdasarkan Tabel 2 dan Tabel 5, diperoleh bahwa nilai rerata derajat inklinasi gigi insisivus mandibula (I.NB) untuk maloklusi Klas I dan Klas II skeletal tidak menunjukkan perbedaan yang signifikan antara kelompok dengan pola pernafasan normal (hidung) dan mulut. Hasil penelitian ini sesuai dengan hasil penelitian Juliano dkk. yang menyatakan bahwa penempatan bibir bawah antara gigi insisivus maksila dan mandibula, karena inklinasi anterior gigi insisivus maksila yang lebih besar dapat menyebabkan tekanan yang berlebih pada basis apikal bawah yang lama-kelamaan dapat menyebabkan gigi insisivus mandibula retroklinasi. ${ }^{2}$ Behfelt juga menemukan kecenderungan terjadinya retroklinasi gigi-gigi anterior mandibula pada pasien yang bernafas melalui mulut. $^{1}$

Berdasarkan Tabel 3 dan Tabel 6, diperoleh nilai rerata sudut interinsisal (I.I) untuk pasien maloklusi Klas I dan Klas II skeletal pada kelompok dengan pola pernafasan melalui mulut lebih kecil dibandingkan dengan pernafasan normal (hidung) dengan perbedaan yang signifikan $(p<0,05)$. Hasil yang diperoleh pada penelitian ini sesuai dengan hasil penelitian yang dilakukan oleh Ascanio dkk. yang memperoleh nilai rerata overjet lebih besar pada kelompok pasien yang bernafas melalui mulut dibandingkan dengan kelompok pasien yang bernafas melalui 
hidung dengan perbedaaan yang signifikan. ${ }^{10}$

Pada Tabel 5, dapat dilihat nilai rerata ukuran linear inklinasi gigi insisivus mandibula (I-NB) untuk pasien maloklusi Klas II pada kelompok dengan pola pernafasan melalui mulut lebih besar dan berbeda secara signifikan. Hasil penelitian ini sesuai dengan hasil penelitian yang dilakukan oleh Cabrera dkk. yang memperoleh perbedaan yang signifikan pada nilai rerata ukuran linear inklinasi gigi insisivus maksila (I-NA) dan mandibula (I-NB). Pada umumnya, pasien yang bernafas melalui mulut cenderung mempunyai maksila yang prognasi, disebabkan perubahan pada posisi lidah yang rendah dan mengganggu keseimbangan dengan otot buksinator. ${ }^{3}$ Penelitian yang dilakukan oleh Juliano dkk. Memperoleh hasil yang berbeda, dimana tidak ditemukan per-

\section{DAFTAR PUSTAKA}

1. Kusuma ARP. Bernafas lewat mulut sebagai faktor ekstrinsik etiologi maloklusi. Majalah Ilmiah Sultan Agung 2010; 48:1-14.

2. Juliano ML, Machado MAC, Carvalho LBC, Prado LBF, Prado GF. Mouth breathing children have cephalometric patterns similar to those of adult patients with obstructive sleep apnea syndrome. Arq Neuropsiquiatr 2009; 67: 860-5.

3. Cabrera LC, Retamoso LB, Mei RMS, Tanaka O. Sagital and vertical aspects of Class II division 1 subjects according to the respiratory pattern. Dental Press J Or-thod 2013: 18(2): 30-5.

4. Abreu RR, Lunardi RR, Lamounier JA, Guerra AFM. Etiology, clinical manifestation and concurrent findings in mouth-breathing children. $\mathrm{J}$ de Pediatria 2008; 84: 530-4.

5. Sheng CM, Lin LH, Su Y, Tsai HH. Developmental changes in pharyngeal airway depth and hyoid bone position from chilhood to young adulthood. Angle Ortodontist 2009; 79: 485-90.

6. Peltomaki T. The effect of mode of breathing on craniofacial growth. Euro-pean J of Orthodontics 2007; 29: 426-9.

7. Cuccia AM, Lotti M, Caradonna D. Oral breathing and head posture. Angle Ortodontist 2008; 78: 78-82.

8. Budianto E, Purwanegara MK, Siregar E. Karakteristik profil jaringan lunak pada penderita obstruksi saluran napas atas de-ngan kebiasaan bernapas melalui mulut. Indonesia J of Dentistry 2008; 15(1): 44-9.

9. Jefferson Y. Mouth breathing: Adverse effect on facial growth, health, academics and behaviour. General Dentistry 2010. Feb 11: 19-23. bedaan signifikan pada nilai rerata derajat dan ukuran linear inklinasi gigi insisivus mandibula antara kelompok bernafas melalui hidung dan mulut. ${ }^{2}$

Sebagai kesimpulan, diperoleh perbedaan yang signifikan untuk nilai rerata derajat dan ukuran linear inklinasi gigi insisivus maksila dan sudut interinsisal antara kelompok dengan pola pernafasan normal (hidung) dan pernafasan melalui mulut $(\mathrm{p}<0,05)$ pada maloklusi Klas I skeletal serta diperoleh perbedaan yang signifikan untuk nilai rerata derajat inklinasi gigi insisivus maksila, ukuran linear gigi insisivus mandibula dan sudut interinsisal antara kelompok dengan pola pernafasan normal (hidung) dan pernafasan melalui mulut $(\mathrm{p}<0,05)$ pada maloklusi Klas II skeletal.

10. Ascanio LD, Lancione C, Pompa G, Rebuffini E, Mansi N, Manzini M. Craniofacial growth in children with nasal septum deviation: A cephalometric comparative study. J Pediatric Otorhino-laryngology 2010; 7(10).

11. Singaraju GS, Kumar C. Tongue thrust habit. Annals and essences of dentistry 2009; 1(2): 14-23.

12. Malhotra S, Pandey RK, Nagar A, Agarwal SP, Gupta VK. The effect of mouth breathing on dentofacial morphology of growing child. J Indian Soc of Pedod Prev Dent 2012; 30(1): 27-31.

13. Lailani TL. Perbedaan lebar saluran udara pharynx atas dan bawah pada maloklusi Klas I dan Klas II dengan pola pertumbuhan normal dan vertikal ditinjau dari radiografi sefalometri lateral. Tesis. Medan: Program Pendidikan Dokter Gigi Spesialis Ortodonsia FKG USU, 2010:1-8.

14. Agrawal Deepesh. Cehalometric analysis for diagnosis and treatment of orthodontic patients. Orthodontic Cyber J 2012: 1-13.

15. Eric W. Radiography and radiology for dental care professionals. $2^{\text {nd }}$ ed., UK: Elsevier., 2009: 141,145-8.

16. Atit MB, Deshmukh SV, Subramaniam V, Naik C, Darda M. Mean values of Steiner, Tweed, Rickets and Mcnamara analysis in Maratha ethnic population: A cephalometric study. APOS Trends in Orthodontics 2013; 3(5): 138-51.

17. Baruah N, Bora M. Cephalometric evaluation based on Steiner's analysis on young adults of Assam. The J of Indian Orthodontic Society 2009; 43(1): 17-22.

18. Naragond A, Kenganal S, Sagarkar R, Kumar S, Sugaradday. Diagnostic limitations of cephalometric in orthodontics. J of Dental and Medical Sciences 2012; 3(1): 30-5. 